\title{
Satisfaction With Chronic Pain Treatment
}

\author{
Parisa Islami Parkoohi ${ }^{1}$; Kimia Amirzadeh ${ }^{2}$; Vahid Mohabbati ${ }^{3}$; Gholamreza Abdollahifard ${ }^{4, *}$ \\ ${ }^{1}$ Department of Community Medicine, School of Medicine, Mazandaran University of Medical Sciences, Sari, Iran \\ ${ }^{2}$ Student Research Committee, Department of Community Medicine, School of Medicine, Shiraz University of Medical Sciences, Shiraz, Iran \\ ${ }^{3}$ Student Research Committee, Department of Community Medicin \\ ${ }^{4}$ School of Medicine, Shiraz University of Medical Sciences, Shiraz, Iran \\ ${ }^{*}$ Corresponding author: Gholamreza Abdollahifard, Department of Community Medicine, School of Medicine, University of Medical Sciences, Shiraz, Iran. Tel: +98-9173167194, Fax: \\ +98-7112347977, E-mail: abdolahigh@sums.ac.ir
}

Received: September 11, 2014; Revised: December 3, 2014; Accepted: January 13, 2015

\begin{abstract}
Background: The effects of chronic pain (СP) on physical function and emotional and mental health of individuals, families, and community are well established. No adequate research is conducted in this field in Iran.

Objectives: The current study aimed to assess the prevalence of $\mathrm{CP}$, types of treatments used for $\mathrm{CP}$ and patients' satisfaction with the $\mathrm{CP}$ treatments in an Iranian urban population.

Patients and Methods: In the current study, CP was investigated using the international CP questionnaire administered to 1,050 adults living in Shiraz, Iran. The questionnaire consisted of 28 questions used to evaluate the effects of $\mathrm{CP}$ on the studied population including the prevalence of $\mathrm{CP}$, pharmacological and non-pharmacological treatments for $\mathrm{CP}$, and participants' satisfaction with CP treatments. All the statistical analyses were performed using SPSS software, version 18.

Results: In the current study, $6.95 \%$ of the 1,050 subjects willing to participate in the study had CP for more than six months. According to the results, $54 \%$ of the subjects with CP used analgesics, mostly non-steroidal anti-inflammatory drugs (NSAIDs) and narcotic analgesics. Besides, $37 \%$ of the subjects used other pain relief methods such as traditional medicine and acupuncture. The results also showed an acceptable rate of satisfaction with treatments.

Conclusions: The number of subjects with $\mathrm{CP}$ proved it as a prevalent problem in the study population. Furthermore, characteristics and associations of those experiencing CP demonstrated that it might have significant negative health and psychosocial outcomes in this group. The problem was found significant enough to consider special health programs to prevent and manage $\mathrm{CP}$ in urban population of Shiraz.
\end{abstract}

Keywords: Chronic Pain; Demographics; Satisfaction; Treatment

\section{Background}

Chronic pain is a common condition, but there is currently no published strong epidemiological data in the Iranian population. chronic pain (CP) has a negative impact on quality of life, including daily functions, efficiency of the immune system, sleep, and nutrition, and can cause mental problems, such as low self-esteem, depression, and hopelessness (1-4). It can lead to an increase absence from work and lack of economic productivity, eventually resulting in an increased demand for more social supportive services, as well as increased financial costs for individuals, families and societies $(1,5)$. In the United States, for instance, 70 million individuals visited physicians and 425 million had the history of using health services for CP each year $(6,7)$. In the United Kingdom, back pain caused 45 million lost working days per year (8).

In a systematic review by Ospina and Harstall on CP (3), the average prevalence of CP was reported to be $35 \%$. A survey by the Canadian health association in 2008, reported the prevalence of CP as 10\% (9). The American national center for health statistics estimated the prevalence of $\mathrm{CP}$ in the American population up to $25 \%$ (10). European figures, based on Breivik et al. (2) report on the impact of CP estimate the prevalence up to $20 \%$ in this population.

Satisfaction with the treatment of CP is investigated in several studies. The results of a review study in Europe showed that $59 \%$ - $77 \%$ of the subjects expressed satisfactory outcomes with their CP treatments (11). Nonetheless, other studies indicated that the rate of CP treatments satisfactory outcomes ranged from $27 \%$ to $42 \%(12,13)$.

Historically, CP management includes pharmacological, non-pharmacological, as well as interventional methods.

\section{Objectives}

Considering the impact of $\mathrm{CP}$, the importance of its management, the lack of appropriate studies on this subject, and patients' satisfaction with the management, the current study attempted an initial assessment of CP in the urban Shiraz population. 


\section{Patients and Methods}

The present study was conducted in 114 postal zones of Shiraz, Iran, in spring 2012. The current paper was the result of a cross-sectional population-based survey conducted in Shiraz. Shiraz is the center of Fars province and is the biggest city in the southern Iran. According to the 2011 national census, Shiraz, with about 1,549,453 populations, is the fifth most populous city in Iran.

The questionnaire used was educed and adjusted from the chronic pain questionnaire used in the "Survey of chronic pain in Europe: prevalence, impact on daily life, and treatment" developed by Breivik et al. (2) with permission from the author. The questionnaire it was applied the same way previously used in the multiple nations with participants of different backgrounds living in different countries, including 15 European countries. Similarities were found between these countries and Iran, including diversities in race and ethnicity and some other common cultural values (2). A professional medical translator first translated the questionnaire into the Persian language then translated the Persian version back into English, to confirm its accuracy. An expert panel evaluated the content validity of the questionnaire, and the reliability was assessed using Cronbach's alpha test $(\alpha=0.83)$.

The multistage sampling method was used, dividing Shiraz city into districts, and then randomly selecting districts as a first step. The districts then were randomly divided into selected blocks. Finally, dwellings on the blocks were randomly selected for participation. The age and gender ratio of the population were also considered.

The first questionnaire was completed through a screening interview within approximately 10 minutes by trained interviewers. The questions examined variables including age, gender, prevalence of $\mathrm{CP}$, intensity and cause of the pain, amount of pharmacological and nonpharmacological treatments, and satisfaction with the administered treatments. Demographics were also examined. Interviewers were trained at a one-day local workshop on how to approach the participants and how to go through the questions with the respondents. Questionnaires were completed using a door-to-door, face-to-face interview by trained interviewers, following a written informed consent. If a person refused to respond, the survey continued with other interviewees until the desired sample size was achieved. The minimum required sample size was calculated to be at least 1,000 participants, according to the previous surveys, to provide adequate power for the study (2).

The inclusion criteria of the study were age greater than 18 years, resident of Shiraz, no history of previous serious mental illness or developmental disabilities.

Inclusion criteria specified the presence of $\mathrm{CP}$ for at least six months and frequency of pain equal to or greater than twice weekly.

\subsection{Statistical Analysis}

All the statistical analyses were performed using the SPSS statistics software (version 18). Results were reported as the means \pm standard deviation (SD) or median for quantitative variables and percentages for categorical variables. The groups were compared using the Student's t-test, ANOVA and Chi-square test for categorical variables. A logistic regression model was applied to define which socio-demographic variables (gender, age, education level and job) had significant effects on chronic pain. A score of $\mathrm{P}<0.05$ was considered significant.

\section{Results}

In the current study, 50.5\% (530/1050) of the subjects were male and 49.5\% (520/1050) were female. Overall, the average age of subjects was 36.53 years ranging from 18 to 78 years. Even though the majority of subjects were less than 40 years old (73.4\%), the prevalence of CP was the greatest in the subjects older than this age group (66\%).

Regarding the educational status, 34.7\% (364/1050) had completed secondary school, whilst 39.2\% (411/1050) had completed tertiary or higher. Most of the subjects were professionals (39\%) and housewives (29.5\%). There was a tendency toward a female preponderance. Characteristics of the subjects with CP are presented in Table 1.

Table 1. The Basic Characteristics of the Subjects With Chronic $\operatorname{Pain}(\mathrm{CP})^{\mathrm{a}}$

\begin{tabular}{lcc}
\hline Variables & All Subjects & CP Subjects \\
\hline Age, $\mathbf{y}$ & & \\
$18-30$ & $467(44.5)$ & $12(17)$ \\
$31-40$ & $303(28.9)$ & $15(20)$ \\
$41-50$ & $114(10.8)$ & $22(30)$ \\
\hline $51 \geq$ & $166(15.8)$ & $24(33)$ \\
\hline Gender & & \\
\hline Male & $530(50.5)$ & $25(34.2)$ \\
\hline Female & $520(49.5)$ & $48(65.8)$ \\
\hline Education level & & \\
\hline School age & $275(26.1)$ & $5(6.8)$ \\
\hline $\begin{array}{l}\text { Diploma (secondary } \\
\text { qualifications) }\end{array}$ & $364(34.7)$ & $42(57.5)$ \\
\hline Bachelor (undergraduate) & $362(34.5)$ & $25(34.3)$ \\
\hline $\begin{array}{l}\text { Master and above (post- } \\
\text { graduate) }\end{array}$ & $49(4.7)$ & $1(1.4)$ \\
\hline Occupation & & \\
\hline Housewife & $142(13.5)$ & $1(1.4)$ \\
\hline Professionals & $310(29.5)$ & $33(45.2)$ \\
\hline Unemployed & $408(39)$ & $34(46.6)$ \\
\hline Student & $190(18)$ & $5(6.8)$ \\
\hline Data & & \\
\hline
\end{tabular}

\footnotetext{
${ }^{\mathrm{a}}$ Data are presented as No.(\%).
} 
According to the obtained results, the prevalence of CP in the sample population was 6.95\% (73/1050), and 82.5\% of the subjects were under some form of treatment. Up to $50 \%$ of the subjects were satisfied with their treatments. Of these $44 \%$ reported very high satisfaction (Table 2 ). Ninety three percent (93\%) of the subjects reported that they complied with the prescribed medications. Pain was reported to be under control by $79.5 \%$ of the subjects, whilst $18 \%$ expressed inadequate management of their pain.

Most of the study subjects used pharmacological treatments for CP(about 90\%). The most commonly consumed analgesic drugs included NSAIDs (25.3\%), narcotic analgesics (17.2\%), beta-blockers (7.5\%), cox-2 inhibitors (3.2\%), and muscle relaxants (3.2\%).

Those who used non-pharmacological treatment numbered 37\% (27/73). Among these patients, the most frequently used techniques included traditional cultural medicine (similar to complementary medicines in western countries), acupuncture, thermotherapy, exercise, and massage (Table 3).

Table 2. The Rate of Satisfaction With Treatments in the Subjects With Chronic Pain ${ }^{\mathrm{a}}$

\begin{tabular}{lc}
\hline Quality of Satisfaction & Values \\
\hline Excellent & $5(7)$ \\
Good & $32(43.8)$ \\
\hline Moderate & $33(45.2)$ \\
Bad & $2(2.7)$ \\
\hline Very bad & $1(1.3)$ \\
Total & $73(100)$ \\
\hline
\end{tabular}

${ }^{\mathrm{a}}$ Data are presented as No. (\%).

Table 3. The Frequency of Non-Pharmacological Treatments in the Subjects With Chronic Pain a,b

\begin{tabular}{lc}
\hline Non-Pharmacological Methods & Values \\
\hline Traditional medicine & $11(20.4)$ \\
\hline Acupuncture & $10(18.5)$ \\
\hline Thermotherapy & $8(14.8)$ \\
Exercise & $7(13)$ \\
\hline Local treatments & $6(11)$ \\
\hline Massage & $5(9.3)$ \\
\hline Nutritional regime & $4(7.4)$ \\
\hline Meditation & $3(5.6)$ \\
\hline Total & $54 \mathrm{~b}(100)$ \\
\hline
\end{tabular}

a Some patients used two or three non-pharmacological methods.

b Data are presented as No. (\%).

\section{Discussion}

$\mathrm{CP}$ is a prevalent problem in many countries. No suitable widespread study is conducted on the prevalence, treatment, and other aspects of CP in Iran. The current study aimed to obtain preliminary information on CP in a large urban population of Iran, examining, treatment methods, satisfaction, and patient characteristics.

Widespread studies show that the prevalence of CP varies in different communities. In a systematic review by Ospina and Harstall on CP (3), the average prevalence of $\mathrm{CP}$ was reported $35 \%$. In the selected sample from urban areas of Shiraz, the prevalence of CP was only 6.95\% (73/1050), which was lower in comparison to the results of most of the previous studies.

world health organization (WHO) data on neurological disorders leading to public health challenges estimated the prevalence of chronic pain ranging from 5\% to 30\% in the adult population of different countries (14). The statistics published by WHO revealed that approximately $20 \%$ of the global population had CP to some degree (15). According to a study on 57,660 individuals aged 12 to 44 years in Canada, the prevalence of CP was 10\%(9). In addition, two other studies performed in the U.S. and 16 European countries indicated that the prevalence of CP was $25 \%$ and $20 \%$, respectively $(2,10)$. Prevalence of CP in these European countries ranged from $12 \%$ in Spain to $30 \%$ in Norway (2). A study in Australia indicated that the prevalence of CP was $18.5 \%$ in the adult population (16).

Comparing the current study data to those of Breivik's (2), obvious limitations accounting to variances and limitation of interpretation include sample size, and geographical location. The current study was single centered, with smaller sample of one cultural group. Breivik's study was a multicenter broader study on 46,000 individuals in 15 different European countries and Israel (17, 18). Despite differences between the studies, the current study results showed significant prevalence of $\mathrm{CP}$ in the study group, encouraging further comprehensive evaluation of CP in Iran.

A potential method to extend sample sizes and locations in Iran would be using telephone, internet and video interviewing technologies. Up to now, several recent studies have used such tools to complete questionnaires successfully (2).

In the study by Breivik et al. (2), $60 \%$ of CP subjects experienced two to nine medical consultations within six months of the study. In the current study, about $77 \%$ of the CP subjects were examined by a general practitioner once or more. In the U.S., 70 million individuals visited doctors for CP and health services were used for CP 425 million times each year $(6,7)$. It can have a big impact on health economies and individuals out of pocket costs $(1,5)$.

In a study conducted in Europe, $40 \%$ of the subjects said that their medical treatments were satisfactory and effective, $41 \%$ believed that medical treatments were sometimes effective, and $15 \%$ indicated that their medical treatments were inadequate and ineffective. In that study, up 
to $77 \%$ of the subjects expressed that their treatments were complete and satisfactory (11). In more recent findings, the patients with CP described $27 \%$ - $42 \%$ of medical treatments as very effective and adequate for their problems $(12,13)$. The current study results were significantly higher especially regarding the levels of treatment satisfaction (44\% - 50\%).

The study by Breivik et al. (2) indicated that $66 \%$ of the subjects were treated by the analgesics prescribed by doctors. These drugs included NSAIDs (44\%), weak opioids (23\%), paracetamol (Acetaminophen) (18\%), COX-2 inhibitors (1 to $36 \%$ ), and strong opioids (5\%). In a study by Perez et al. $66 \%$ of the subjects were under pharmacological treatments (19). Gamero et al. (20) estimated that NSAIDs (57\%), paracetamol (29\% - 32\%), and opioids (6.4\%) were used more frequently to treat CP. The current study results showed that $54 \%$ of the subjects used common over the counter analgesics, including NSAIDs (25.3\%), narcotic analgesics (17.2\%), and beta blockers (7.5\%). These findings are comparable with those of other studies, such as the one by Breivik et al. (2).

Breivik et al. (2), demonstrated that two-thirds of the subjects with CP also used other treatment modalities such as massage therapy (30\%), physical therapy (21\%), and acupuncture (13\%), with or without drug therapy. Similarly, Gamero et al. (20) showed that 33\% - 35\% of the subjects used non-drug treatments, such as massage ( $9 \%$ $-15 \%)$ and physical therapies (7\% - 8\%). Rodriguez et al. (21) showed that $51 \%$ of the subjects used complementary therapies . In the current study, 37\% of the subjects used non-pharmacological treatments, including traditional cultural medicine (20.4\%), acupuncture (18.5\%), thermotherapy (15\%), and exercise (13\%). The rate of non-drug therapy use in the study (37\%) is in agreement with the findings of the study by Gamero et al. (33\% - 35\%) (20). In the study by Breivik et al. (2), a greater number of the subjects with CP used non-pharmacological treatments (66\%). These disparities could be due to health literacy, cultural issues or level of acceptance of non-pharmacological treatments as the main method to treat $\mathrm{CP}$ in different countries.

There were some limitations in the current study. The prevalence of subtypes of chronic pain such as neuropathic, nociceptive or inflammatory pain was not investigated. The prevalence could be affected by limitations in capturing all pain populations. For example, cognitively impaired and nursing home residents or patients with cancer could not be included. The current study was based on that of Breivik's, which defined the duration of chronic pain in the current study is considered at least six months, and this could have an impact on the prevalence of CP when compared with those of the other studies. Some studies used three months or less as a trigger for inclusion in $\mathrm{CP}(16)$.

The face-to-face nature of the interviews is considered as strength of the study. However, the timing of the interviews could have a negative impact, since interviews were conducted on the week-days and in working hours, which is likely to include less men or working participants. Most of the overseas studies were conducted using a telephone or computer-based interview system, which may also have implications on the CP assessment (2). There are well-established biases created in any telephone interviews. Only those people listed in the telephone directories were included. Females were more likely to answer the telephone and more willing to cooperate and take part in a survey than the males, and there was also a greater likelihood that the elderly were at home than a young person (2).

The current study demonstrated $6.95 \%$ prevalence for CP in Shiraz, Iran. Authors expected a higher rate, given that Iran has been through much turmoil in recent decades including an eight-year war, many natural disasters such as earthquakes and a very high rate of road accidents. Pain medicine is a young specialty and is introduced as a postgraduate fellowship in recent years. There seems to be a growing recognition of $\mathrm{CP}$ amongst patients and health practitioners. Findings of the current study can contribute to better recognition of $\mathrm{CP}$ as a significant health care issue in Iran.

Larger population based studies at a national level are needed to gain more accurate data on $\mathrm{CP}$, and also explore other aspects of chronic pain including cancer-related chronic pain, neuropathic pain, health related costs etc. in Iranian communities. Therefore, health policy makers will have a better overview to consider appropriate policies to tackle this issue.

\section{Acknowledgements}

The present article was extracted from a thesis written by Kimia Amirzadeh and was financially supported by Shiraz University of Medical Sciences grants No. 90 -3767.

\section{Funding/Support}

This study was funded by Shiraz University of Medical Sciences grant no. 3767.

\section{References}

1. Niv D, Devor M. Chronic pain as a disease in its own right. Pain Pract. 2004;4(3):179-81.

2. Breivik H, Collett B, Ventafridda V, Cohen R, Gallacher D. Survey of chronic pain in Europe: prevalence, impact on daily life, and treatment. EurJ Pain. 2006;10(4):287-333.

3. Ospina M, Harstall C. Multidisciplinary pain programs for chronic pain: evidence from systematic reviews.: Alberta Heritage Found Med Res; 2003.

4. Kemler MA, Furnée CA. The Impact of Chronic Pain on Life in the Household. J Pain Symp Manag. 2002;23(5):433-41.

5. Breivik H, Borchgrevink PC, Allen SM, Rosseland LA, Romundstad L, Hals EK, et al. Assessment of pain. BrJAnaesth. 2008;101(1):17-24

6. Eisenberg DM, Kessler RC, Foster C, Norlock FE, Calkins DR, Delbanco TL. Unconventional medicine in the United States. Prevalence, costs, and patterns of use. NEngl J Med.1993;328(4):246-52.

7. Gardea MA, Gatchel RJ. Interdisciplinary treatment of chronic pain. Curr Rev Pain. 2000;4(1):18-23.

8. Smith BH, Elliott AM, Chambers WA, Smith WC, Hannaford PC 
Penny K. The impact of chronic pain in the community. Family Practice. 2001;18(3):292-9.

9. Mc-Allister J. Chronic pain in youth: chronic pain afflicts $1.5 \mathrm{mil}$ lion young Canadians.. Available from: http://thechemicaledge. com/2011/02/06/chronic-pain-in-youth/

10. U.S. Department of Health and Human Service. Health, United States, 2006 with Chart book on Trends in the Health of Americans. Hyattsville: Nat C Health Statis; 2006.

11. Leverence RR, Williams RL, Potter M, Fernald D, Unverzagt M, Pace W, et al. Chronic non-cancer pain: a siren for primary care--a report from the PRImary Care MultiEthnic Network (PRIME Net). JAm Board Fam Med. 2011;24(5):551-61.

12. Tolle T, Xu X, Sadosky AB. Painful diabetic neuropathy: a crosssectional survey of health state impairment and treatment patterns. J Diabetes Complications. 2006;20(1):26-33.

13. van Seventer R, Sadosky A, Lucero M, Dukes E. A cross-sectional survey of health state impairment and treatment patterns in patients with postherpetic neuralgia. Age Ageing. 2006;35(2):132-7.

14. World Health Organization. Neurological disorders: Public health challenges. Vol. 3. Geneva: WHO; 2006. p. 131.

15. Gureje O, Von Korff M, Simon GE, Gater R. Persistent Pain and Well-being. JAMA. 1998;280(2):147.
16. Blyth FM, March LM, Brnabic AJM, Jorm LR, Williamson M, Cousins MJ. Chronic pain in Australia: a prevalence study. Pain. 2001;89(2):127-34.

17. Sicras-Mainar A, Blanca-Tamayo M, Navarro-Artieda R, RejasGutierrez J. [Use of resources and costs profile in patients with fibromyalgia or generalized anxiety disorder in primary care settings]. Aten Primaria. 2009;41(2):77-84.

18. Miro J, Paredes S, Rull M, Queral R, Miralles R, Nieto R, et al. Pain in older adults: a prevalence study in the Mediterranean region of Catalonia. Eur JPain. 2007;11(1):83-92.

19. Perez C, Saldana MT, Navarro A, Vilardaga I, Rejas J. Prevalence and characterization of neuropathic pain in a primary-care setting in Spain: a cross-sectional, multicentre, observational study. Clin Drug Investig. 2009;29(7):441-50.

20. Gamero RF, Gabriel SR, Carbonell AJ, Tornero MJ, SánchezMagro I. [Pain in Spanish rheumatology outpatient offices: EPIDOR epidemiological study]. Revista clinica espanola. 2005;205(4):157-63.

21. Rodriguez MJ, Camba A, Barutell C, Gonzalez-Escalada JR. Survey of therapeutic attitudes for the treatment of chronic pain in Spanish Pain Units. The STEP study. Revista de la Sociedad Espanola del Dolor. 2006;13(8):525-32. 